\title{
Pemodelan Tsunami di Sekitar Laut Banda dan Implikasi Inundasi di Area Terdampak
}

\author{
Nisrina Ikbar Rahmawati ${ }^{1}$, Bagus Jaya Santosa ${ }^{1}$, Wiko Setyonegoro ${ }^{2}$, dan Bambang Sunardi ${ }^{2}$ \\ ${ }^{1}$ Departemen Fisika, Fakultas Matematika dan Ilmu Pengetahuan Alam, Institut Teknologi Sepuluh Nopember (ITS) \\ ${ }^{2}$ Pusat Penelitian dan Pengembangan, Badan Meteorologi Klimatologi dan Geofisika, \\ e-mail: bjs@physics.its.ac.id
}

\begin{abstract}
Abstrak-Hasil penelitian memperlihatkan bahwa $67 \%$ tsunami terjadi di Indonesia timur, salah satunya di sekitar laut Banda. Penelitian terbaru membuktikan adanya palung terdalam Indonesia di Laut Banda, yang pernah memicu tsunami besar pada tahun 1674. Oleh karena itu, pemodelan tsunami di wilayah tersebut penting dilakukan sebagai upaya mitigasi tsunami di masa datang. Penelitian ini bertujuan untuk memodelkan sumber, penjalaran dan run-up tsunami di sekitar Laut Banda serta menganalisis inundasi di area terdampak menggunakan software L2008. Pemodelan tsunami dilakukan menggunakan skenario gempabumi 26 Desember 2009 dengan memodifikasi kekuatan menjadi $M w=8.3$, kedalaman $33 \mathrm{~km}$ dan mekanisme sumber gempabumi ditentukan dengan software ISOLA. Dimensi patahan dan slip diperkirakan menggunakan persamaan empiris dari Papzachos (2004), Hanks and Kanamori (1979) dan Wells \& Coppersmith (1984). Analisis inundasi mengacu pada persamaan Hills, J. G. \& Mader, C. L., 1997. Hasil pemodelan tsunami menunjukkan nilai vertical displacement maksimal sekitar 7,7 m, penjalaran tsunami ke segala arah dan pertama kali memasuki daerah Seram bagian timur pada menit ke 05.40. Run up tertinggi dijumpai di Tual sekitar 7,71 $\mathrm{m}$ dan inundasi tsunami berkisar antara 64,18 m di Kepulauan Aru hingga 1.009,49 m di Kota Tual.
\end{abstract}

Kata Kunci-Inundasi, L2008, Pemodelan Tsunami, Run Up.

\section{PENDAHULUAN}

$\mathrm{P}$ ENINGKATAN frekuensi kejadian tsunami yang terjadi di Indonesia cukup banyak, khususnya Indonesia bagian Timur sejak tahun 1975 semakin menegaskan bahwa kompleksnya tatanan tektonik di daerah ini menyimpan potensi tsunami yang cukup besar. Karakteristik gempa pembangkit tsunami di Indonesia menunjukkan bahwa 67\% tsunami berada di Indonesia bagian Timur dan ditunjukkan bahwa pada $115^{\circ}$ BT sampai $139^{\circ}$ BT yang tersebar merata dari Sulawesi sampai Papua dan dari Timor sampai kepulauan Sangihe Talaud (Gambar 1). Selama periode waktu antara tahun 1600 sampai 2004 telah terjadi kurang lebih 109 tsunami di Indonesia bagian Timur[1].

Tsunami tidak termasuk dalam gelombang tunggal tapi berupa rangkaian gelombang pada laut dalam yang mana tinggi gelombangnnya hanya sampai 0,5 meter, namun sewaktu mendekati pantai tingginya sampai 15 meter bahkan lebih besar. Tsunami mempunyai gaya yang sangat besar karena volume air yang sangat besar dan pengaruh kecepatannya. Kecepatannya mendekati pantai sekitar 48 $\mathrm{km} / \mathrm{jam}$ namun kekuatannya jutaan ton [2].

Tinggi tsunami disebabkan karena terjadinya konversi energi kinetik gelombang menjadi energi potensial. Artinya, kehilangan energi akibat berkurangnya kecepatan ditransfer ke dalam bentuk pembesaran tinggi gelombang (run up)[3]. Secara umum faktor penyebab terjadinya tsunami adalah gempa tektonik, letusan vulkanik, longsoran (landslide), dll. Dimana karakteristik gempa yang dapat menimbulkan tsunami adalah sebagai berikut:

1. Episenter (Pusat gempa) berada di laut.

2. Kedalaman pusat gempa (hiposenter) adalah dangkal, pada umumnya kurang dari $60 \mathrm{~km}$ dari permukaan .

3. Mekanisme patahan gempa tektonik bertipe sesar naik (reverse fault) atau sesar turun (normal fault).

4. Magnitudo gempa besar, pada umumnya di atas $M=7 \mathrm{SR}$.

5. Batimetri, kelandaian, dan bentuk dari pantai yang sesuai.

6. Gerakan vertikal ini dapat terjadi pada patahan bumi atau sesar ketika hal ini terjadi air laut akan berupaya untuk kembali pada kondisi seimbang mengikuti gravitasi. Sehingga gerakan ini akan menyebabkna terjadinya energi yang dapat mendorong gelombang laut naik secara vertikal dan memunculkan tsunami [3].

Bencana tsunami biasanya dibangkitkan di perairan yang dalam kemudian menjalar ke perairan yang lebih dangkal. Saat telah memasuki perairan yang dangkal, tsunami kemudian akan mengalami transformasi gelombang, sehingga akan menghasilkan beberapa parameter. Parameter-parameter akibat tranformasi tersebut adalah tinggi tsunami, run up tsunami, dan genangan (inundation), seperti yang ditunjukkan pada Gambar 1[4]. Dispersi juga diamati untuk gelombang tsunami, yang mana gelombang airnya yang dihasilkan oleh gempa bumi [5]. Tsunami seperti gelombang air yang digerakkan angin, di dalamnya melibatkan energi potensial gravitasi yang tersimpan oleh perpindahan vertikal air [6]. 


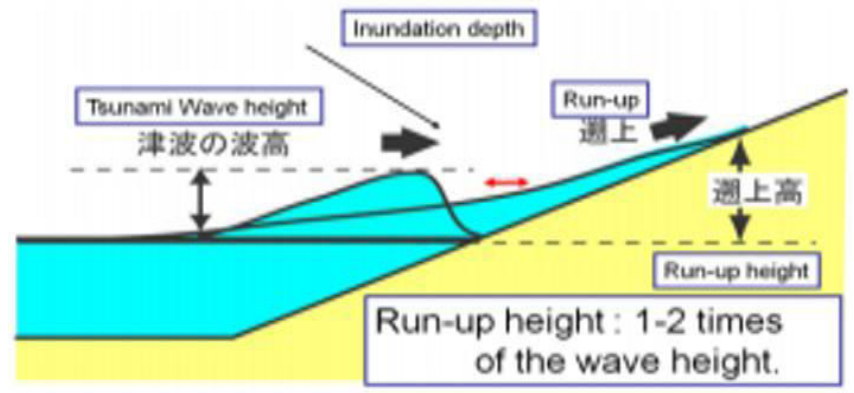

Gambar 1. Parameter Tsunami [4].

Sebuah gempa yang besar dapat menghasilkan gerakan tanah yang dapat dicatat hampir di seluruh permukaan bumi. Dimana gempa yang dapat membangkitkan tsunami (tsunamigenic earthquake) untuk menghasilkan deformasi di dasar laut harus gempa yang memiliki momen seismik yang besar dengan posisi episenter yang dangkal. Momen seismik menghitung besarnya energi yang dilepaskan oleh gempa dengan memperhitungksn perpindahan yang terjadi di dalam slip di sepanjang sesar dan luas permukaan sesar yang mengalami slip. Megnitudo gempa tidak cocok untuk digunakan dalam gempa yang memiliki skala kecil, karena perpindahan dalam slipnya relatif lebih kecil atau bahkan kurang signifikan. Hubungan antara momen seismik dan deformasi seperti dilihat pada persamaan berikut ini:

$$
M o=\mu \cdot A \cdot D
$$$$
\text { dimana : }
$$

Mo $=$ momen seismic gempa $(\mathrm{Mm})$

$\mu=\operatorname{rigiditas}\left(\mathrm{N} / \mathrm{m}^{2}\right)$

A $=$ luas bidang sesar $\left(\mathrm{m}^{2}\right)$

$\mathrm{D}=$ deformasi atau dislokasi $(\mathrm{m})[7]$

Adapun hubungan antara magnitudo gempa dengan momen seismik menurut persamaan

$$
M w=\frac{2}{3} \log M o-6,07[8]
$$

Beberapa parameter gempa yang perlu diketahui dalam hubungannya dengan pembentukan tsunami adalah momen seismik, lokasi atau episenter pusat gempa, kedalaman pusat gempa, dan mekanisme fokus serta geometri sesar [9].

Sedangkan untuk panjang dan lebar dari deformasi dapat ditentukan dari daerah distribusi terjadinya gempa utama (main shock), gempa-gempa kecil sebelum gempa utam (fore shock), dan gempa-gempa susulan (after shock). Magnitudo dari foreshock dan aftershock selalu lebih kecil daripada mainshock.

Secara empiris panjang, lebar dan slip fault dapat ditentukan dengan melakukan interpolasi berdasakan persamaan sebagai berikut [10]:

a. Panjang Sesar (L)

$$
\log \mathrm{L}=-2,42+(0,58 * \mathrm{Mw})
$$

b. Lebar Sesar

$$
\log W=-1,61+(0,41 * \mathrm{Mw})
$$

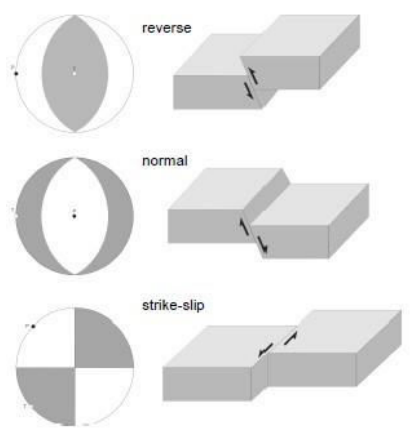

Gambar 2. Tiga Macam Bentuk Gerakan Dasar Sesar [4].

$$
\log \mathrm{MD}=-1,38+(1,02 * \log \mathrm{L})
$$

d. Average Displacement

$$
\log A D=-1,43+(0,88 * \log \mathrm{L})[9]
$$

Gempa tektonik terjadi akibat terjadinya proses lempeng yang berupa pergeseran, tumbukan, pelipatan atau penyusupan yang dapat mempengaruhi media yang dilewati dalam proses tersebut. Di daerah pertemuan lempeng akan timbul suatu tegangan yang diakibatkan oleh tumbukan dan pergeseran antara lempeng serta sifat-sifat elastisitas dari batauan. Tegangan drai batuan-batuan tersebut akan terkumpul secara terus-menerus sehingga sesuai dengan karakteristik batuan hingga mencapai titik patah. Secara umum solusi untuk mekanisme fokus yang dinyatakan dalam proyeksi stereografik dengan tiga macam sesar yaitu, sesar mendatar, sesar normal dan sesar naik bisa dilihat seperti pada Gambar 2 di bawah ini:

Untuk solusi momen tensor bisa didapatkan dari seismogram, dan seismogram dapat mencatat waktu tiba dan amplitudo milik bebrpa fase gelombang utama dan hubungannya dengan dispersi kecepatan-perioda pada gelombang permukaan. Dimana solusi CMT atas gempa dikerjakan pada seismogram dengan periode pendek [11].

\section{II.METODOLOGI PENELITIAN}

Dalam penelitian ini dilakukan pemodelan tsunami untuk daerah di Laut Banda, di sekitar palung Weber. Data yang digunakan adalah data mekanisme fokus gempa yang terjadi di sekitar Palung Weber pada tanggal 26 Desember 2009 berdasarkan skenario sumber gempa dari USGS dan data batimetri ETOPO 2 dengan batas koordinat $125^{\circ}-135^{\circ} \mathrm{BT}$ dan $1^{0} \mathrm{LU}-9^{0} \mathrm{LS}$.

Pada penelitian ini dilakukan pengumpulan beberapa sumber referensi untuk pemodelan tsunami dan beberapa data mekanisme sumber gempa serta data batimetri. Adapun input yang dibutuhkan dalam penelitian ini adalah parameter gempa (lokasi episenter, magnitudo, panjang dan lebar sesar, strike, dip, dan slip). Dimana pada penelitian ini strike dan dip didapatkan dari hasil simulasi menggunakan software ISOLA, dengan data tiga stasiun dari GFZ. Semua data dikumpulkan dari berbagai sumber agar lebih akurat dalam melakukan pemodelan tsunami. Tahapan-tahapan dalam penelitian ini adalah:

c. Maximum Dispalcement (MD) 


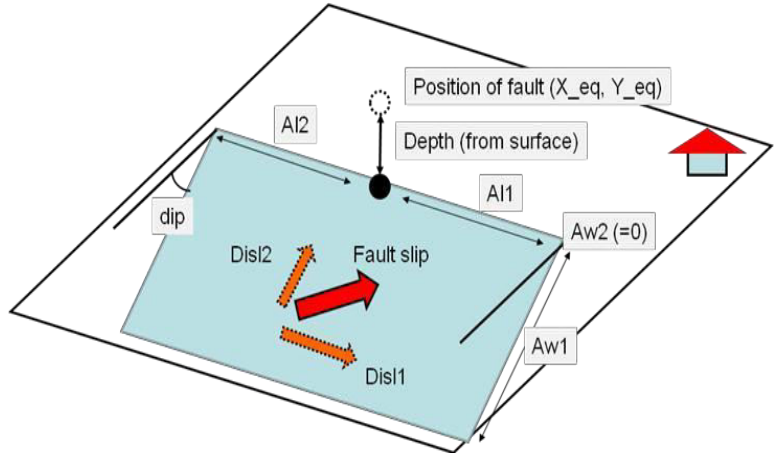

Gambar 3. Setting Parameter Untuk Source Modeling.

\section{A. Desain Model (Source Modeling)}

Titik awal sumber tsunami diperoleh dengan memperkirakannya sebagai deformasi yang terjadi di dasar laut dengan parameter patahan yang ditentukan menggunakan mekanisme sumber gempa. Dalam penelitian ini mekanisme sumber gempa yang digunakan adalah data hasil running menggunakan software ISOLA. Dimensi dari deformasi dapat diperkirakan dengan menggunakan perumusan empiris sehingga akan dapat diperkirakan panjang, lebar, dan luas fault serta slip yang dihasilkan [7], [8], dan [10].

\section{B. Model Penjalaran Gelombang (Ocean Modeling)}

Data yang dibutuhkan dalam ocean modeling ini adalah data output dari source modeling dengan data batimetri. Untuk mendapatkan hasil simulasi yang baik, maka dibutuhkan data batimetri yang sesuai dan tepat dengan daerah penelitian. Pada penelitian ini data batimetri yang digunakan adalah ETOPO 2 [12]. Data batimetri untuk inpuut di software tsunami L2008 harus dengan format '*.xyz' (Lon Lat Depth).

\section{Pemodelan Run Up Tsunami (Run Up Modeling)}

Pada penelitian ini dilakukan pemodelan ketinggian tsunami (run up modelling). Pada run up modeling ini dilakukan dengan digitasi pada daerah-daerah yang telah ditentukan, untuk diketahui nilai run up nya.

\section{D.Analisis Inundasi Area Terdampak}

Analisis inundasi untuk area terdampak tsunami berdasarkan beberapa wilayah kabupaten di Maluku. Analisis ini dilakukan dengan menggunakan perumusan inundasi berdasarkan run up tsunami dihitung oleh Hills, J. G. \& Mader, C. L. 1997, dengan persamaan sebagai berikut [13] :

$$
X \max =(H s)^{1.3 a} \times n^{-2} \times k
$$

dimana :

Xmax : Inundasi maksimum (m),

Hs : Run-up tsunami maksimum (m),

$\mathrm{k}$ : konstanta $(0,06$ selama bertahun-tsunami),

$\mathrm{n} \quad$ : konstan (0.015 untuk daerah halus, 0,03 untuk kawasan bangunan dan, 0,07 untuk kawasan hutan)[13].

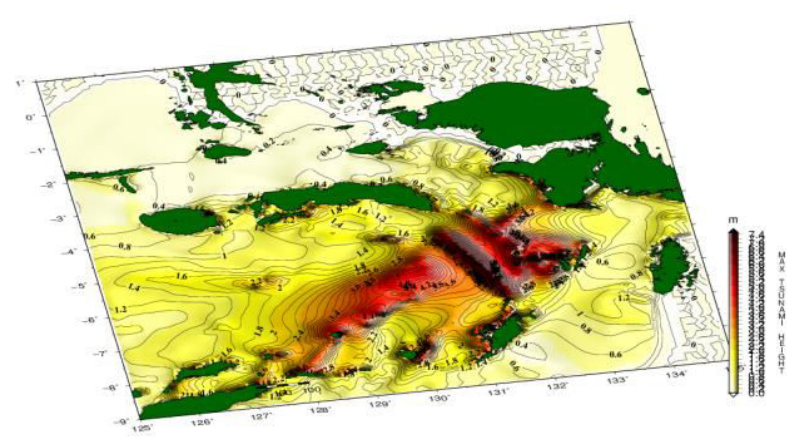

Gambar 4. Hasil Run up Modeling.

\section{HASIL DAN PEMBAHASAN}

Hasil dari source modeling mengGambarkan variasi nilai maximum vertical displacemant untuk event ini adalah 7,7 meter dan nilai minimum vertical displacement sebesar $-7,7 \mathrm{~m}$. Dari nilai (+) maximum vertical displacemant menunjukkan terjadinya pergerakan vertikal lantai samudera naik, sedangkan untuk nilai (-) minimum vertical displacement menunjukkan terjadinya pergerakan vertikal lantai samudera turun.

Seanjutnya, pada hasil analisa penjalaran gelombang (ocean modeling) menunjukkan gelombang tsunami menjalar dari sumber gempa ke segala arah. Dalam penelitian ini daerah yang terkena gelombang tsunami lebih dulu adalah Seram Bagian Timur pada menit ke 05.40. Adanya perbedaan waktu dalam penjalaran gelombang tsunami ini disebabkan oleh beberapa faktor, seperti kondisi batimetri bawah permukaan laut wilayah persebaran tsunami yang berbeda-beda dan tingkat kelandaian pantai.

Hasil run up modeling menunjukkan tsunami menjalar di sepanjang pantai di sekitar wilayah Maluku, seperti ditunjukkan pada Gambar 4. Nilai run up tertinggi berdasarkan model terjadi di sekitar kabupaten Tual dengan kisaran nilai 7,71 meter. Berdasarkan penelitian yang telah dilakukan, run up tsunami di setiap daerah memiliki nilai yang berbeda-beda hal ini disebabkan salah satunya karena jarak episenter gempa ke setiap daerah itu berbeda-beda. Nilai run up tsunami di masing-masing daerah yang berbeda-beda menyebabkan perbedaan inundasi yang ditimbulkan. Inundasi merupakan jarak maksimum run up atau jarak maksimum air yang sampai ke daratan akibat penjalaran gelombang tsunami.

Dalam penelitian ini, dilakukan analisa antara tinggi run up tsunami dengan inundasi yang dihasilkan. Panjang inundasi akan mempengaruhi juga pada banyaknya populasi penduduk yang terdampak oleh gelombang tsunami. Dimana panjang inundasi akan bernilai semakin besar, ketika tinggi tsunami mencapai nilai maksimum.

Nilai run up tidak hanya dipengaruhi oleh jarak episenter gempa ke suatu daerah terdampak, melainkan dipengaruhi juga oleh beberapa faktor lain seperti batimetri, bentuk pantai, kelandaian pantai dan tinggi gelombang tsunami. Tinggi gelombang tsunami akan mengalami peningkatan sebanding dengan kedangkalan atau saat mendekati daratan. Fenomena 
tersebut akan diikuti oleh adanya refraksi, refleksi dan difraksi sehingga menjadikan gelombang tsunami semakin tinggi.

\section{KESIMPULAN}

Berdasarkan penelitian yang telah dilakukan, diperoleh kesimpulan sebagai berikut :

1. Hasil pemodelan sumber (source modeling), penjalaran gelombang tsunami (ocean modeling), dan ketinggian tsunami (run-up modeling), yaitu:

a. Vertical displacement maksimal adalah 7,7 meter dan. Vertical displacement minimum adalah -7,7 meter.

b. Penjalaran gelombang tsunami ke segala arah, dimana daerah yang pertama kali terkena tsunami adalah daerah Seram bagian timur pada menit ke 05.40.

c. Run up tertinggi berdasarkan model terjadi di Maluku Tenggara dengan ketinggian sekitar 7,71 meter.

2. Hasil analisis inundasi diperoleh perkiraan panjang inundasi terbesar adalah kota Tual dengan nilai 1009,49 meter.

\section{UCAPAN TERIMA KASIH}

Penulis Nisrina Ikbar Rahmawatii mengucapkan terima kasih banyak kepada Badan Meteorologi Klimatologi dan Geofisika (BMKG) yang telah menyediakan data penelitian serta seluruh staff di Puslitbang BMKG yang telah mendantu penelitian penulis.

\section{DAFTAR PUSTAKA}

[1] G. Ibrahim and Subardjo, "Pengetahuan Seismologi," Jakarta, 2005.

[2] UNESCO-IOC, "Tsunami Glossary: IOC Information Document No. 1221," 2006. [Online]. Available: www.shoa.cl.

[3] S. Disaptono and Budiman, Tsunami. Buku Ilmiah Populer. Bogor: ITB, 2006.

[4] M. Nakamura, "Source fault model of the 1771 Yaeyama Tsunami Southern Ryukyu island Japan Inferred from Numerical Simulation," Pure Appl. Geophys, vol. 163, pp. 41-54, 2006.

[5] J. P. Eaton, D. H. Richter, and W. U. Ault, "The tsunami of May 23, 1960 on the island of Hawaii," Bull. Seism. Soc. Am., vol. 51, pp. 135$57,1961$.

[6] S. Ward, The Encyclopedia of Solid Earth Geophysics. New York: Van Nostrand-Reinhold, 1989.

[7] Hanks, C. Thomas, and H. Kanamori, "Moment magnitude scale," $J$. Geophys. Res., vol. 84, pp. 2348-2350, 1979.

[8] D. L. Wells and K. J. Coppersmith, "New empirical relationships among magnitude, rupture length, rupture width, and surface displacements," Bull. Seismol. Soc. Am., vol. 84, no. 974-1002, 1994.

[9] L. Madrinovella, S. Widiyantoro, and Irwan Meilano, "Reloksi Hiposenter Gempa Padang 30 September 2009 Menggunakan Metode Double Difference," JTM, vol. 17, no. 1, 2011.

[10]B. C. Papazachos, C. B. Scordilis, E. M., Panagiotopoulos, D. G., Papazachos, and G. F. Karakaisis, "Global Relations between Seismic Fault Parameters and Moment Magnitude of Earthquakes," in Proceedings of the 10 International Congress, 2004.

[11]B. J. S., "Pengujian Model Bumi Referensi dan Solusi CMT gempa C081097A dan B122500C melalui Perbandingan Seismogram 3Komponen di Stasiun-stasiun Observasi di Australia," J. Fis. dan Apl, vol. 6 , no. $2,2010$.

[12]Anonymous, "No Title." [Online]. Available: http://www.bluemarblegeo.com/products/global-mapper-formatselevation.

[13]J. G. Hills and L. Mader, C, "Tsunami producted by the impacts of the small asteroids," 1997. 